\title{
Reducing chemotherapy use in clinically high-risk, genomically low-risk pN0 and pN1 early breast cancer patients: five-year data from the prospective, randomised phase 3 West German Study Group (WSG) PlanB trial
}

\author{
Ulrike Nitz $^{1,2} \cdot$ Oleg Gluz $^{1,2}$ (D) Matthias Christgen ${ }^{3} \cdot$ Ronald E. Kates $^{1}$ • \\ Michael Clemens ${ }^{4} \cdot$ Wolfram Malter $^{5} \cdot$ Benno Nuding $^{6} \cdot$ Bahriye Aktas $^{7}$ • \\ Sherko Kuemmel $^{8}$ - Toralf Reimer' ${ }^{9}$ Andrea Stefek ${ }^{10}$ - Fatemeh Lorenz-Salehi ${ }^{11}$. \\ Petra Krabisch $^{12} \cdot$ Marianne Just $^{13}$ - Doris Augustin ${ }^{14}$ - Cornelia Liedtke $^{1,15}$. \\ Calvin Chao $^{16}$ - Steven Shak ${ }^{16}$ - Rachel Wuerstlein ${ }^{1,17} \cdot$ Hans H. Kreipe $^{3}$. \\ Nadia Harbeck ${ }^{1,17}$
}

Received: 16 June 2017/ Accepted: 23 June 2017/Published online: 29 June 2017

(C) The Author(s) 2018, corrected publication 2019

\begin{abstract}
Background The prospective phase 3 PlanB trial used the Oncotype DX ${ }^{\circledR}$ Recurrence Score ${ }^{\circledR}$ (RS) to define a genomically low-risk subset of clinically high-risk pN0-1 early breast cancer (EBC) patients for treatment with adjuvant endocrine therapy (ET) alone. Here, we report five-year data evaluating the prognostic value of RS, Ki-67, and other traditional clinicopathological parameters.
\end{abstract}

Ulrike Nitz and Oleg Gluz have equally contributed to this work.

Oleg Gluz

oleg.gluz@wsg-online.com

1 West German Study Group, Ludwig-Weber-Str. 15, 41061 Moenchengladbach, Germany

2 Ev. Hospital Bethesda, Breast Center Niederrhein, LudwigWeber-Str. 15, 41061 Moenchengladbach, Germany

3 Institute of Pathology, Medical School Hannover, CarlNeuberg-Str. 1., 30625 Hannover, Germany

4 Department of Oncology, Clinics Mutterhaus der Borromäerinnen, Feldstraße 16, 54290 Trier, Germany

5 Department of Gynecology and Obstetrics, Breast Center, University Clinics Cologne, Kerpener Str. 62, 50937 Cologne, Germany

6 Department of Gynecology and Obstetrics, Evangelical Hospital, Ferrenbergstraße 24, 51465 Bergisch Gladbach, Germany

7 Department of Gynecology and Obstetrics, University Clinics Essen, Hufelandstraße 55, 45147 Essen, Germany

8 Clinics Essen-Mitte, Breast Centre, Henricistraße 92, 45136 Essen, Germany
Methods A central tumour bank was prospectively established within PlanB. Following an early amendment, hormone receptor $(\mathrm{HR})+, \mathrm{pN} 0-1 \mathrm{RS} \leq 11$ patients were recommended to omit chemotherapy. Patients with $\mathrm{RS} \geq 12$, pN2-3, or HR-negative/HER2-negative disease were randomised to anthracycline-containing or anthracycline-free chemotherapy. Primary endpoint: disease-free survival (DFS). PlanB Clinicaltrials.gov identifier: NCT01049425.

Findings From 2009 to 2011, PlanB enrolled 3198 patients (central tumour bank, $\mathrm{n}=3073$ ) with the median age of

9 Department of Gynecology and Obstetrics, Clinics Suedstadt, Südring 81, 18059 Rostock, Germany

10 Johanniter Clinics Stendal, Breast Center Altmark, Bahnhofstraße 24 - 26, 39576 Stendal, Germany

11 Department of Gynecology, Dr. Horst-Schmidt Clinics, Ludwig-Erhard-Straße 100, 65199 Wiesbaden, Germany

12 Klinikum ChemnitzFlemmingstraße 2, 09116 Chemnitz, Germany

13 Oncological Practice, Teutoburger Str. 60 33604, Bielefeld, Germany

14 Breast Centre Ostbayern, Perlasberger Str. 41, 94469 Deggendorf, Germany

15 Department of Gynecology and Obstetrics, University Hospital Schleswig-Holstein Campus Luebeck, Ratzeburger Allee 160, 23562 Luebeck, Germany

16 Genomic Health, Inc., Redwood City, CA, USA

17 Department of Gynecology and Obstetrics, Breast Center, University of Munich (LMU) and CCCLMU, Munich, Germany 
56 years, $41.1 \% \mathrm{pN}+$, and $32.5 \%$ grade $3 \mathrm{EBC}$. Chemotherapy was omitted in $348 / 404(86.1 \%)$ eligible $\mathrm{RS} \leq 11$ patients. After 55 months of median follow-up, five-year DFS in ET-treated RS $\leq 11$ patients was $94 \%$ (in both pN0 and pN1) versus 94\% (RS 12-25) and 84\% $(\mathrm{RS}>25)$ in chemotherapy-treated patients $(p<0.001)$; five-year overall survival (OS) was 99 versus $97 \%$ and $93 \%$, respectively $(p<0.001)$. Nodal status, central/local grade, tumour size, continuous $\mathrm{Ki}-67$, progesterone receptor (PR), IHC4, and RS were univariate prognostic factors for DFS. In a multivariate analysis including all univariate prognostic markers, only pN2-3, central and local grade 3, tumour size $>2 \mathrm{~cm}$, and RS, but not IHC4 or Ki-67 were independent adverse factors. If RS was excluded, IHC4 or both Ki-67 and PR entered the model. The impact of RS was particularly pronounced in patients with intermediate Ki-67 $(>10 \%,<40 \%)$ tumours.

Interpretation The excellent five-year outcomes in clinically high-risk, genomically low-risk $(\mathrm{RS} \leq 11)$ pN0-1 patients without adjuvant chemotherapy support using RS with standardised pathology for treatment decisions in HR+ HER2-negative EBC. Ki-67 has the potential to support patient selection for genomic testing.

Keywords Genomic signature - Oncotype DX - Breast cancer $\cdot \mathrm{Ki}-67 \cdot \mathrm{IHC} 4$

\section{Introduction}

Adjuvant treatment decisions in hormone receptor (HR)+l HER2-negative early breast cancer (EBC) have traditionally relied on clinicopathological characteristics (nodal status, tumour size/grade, age, and co-morbidities). A recent meta-analysis of standard chemotherapy (CT) regimens demonstrated that proportional risk reductions were little affected by age, nodal status, tumour diameter/differentiation, ER status, and tamoxifen use [1].

Increasing evidence suggests that HR+/HER2-negative $\mathrm{EBC}$ is a heterogeneous disease [2]. Specifically, patients with molecularly classified [2] luminal-A or immunohistochemically (IHC) classified (Ki-67, progesterone receptor (PR)) luminal-A-like tumours have excellent prognosis [3-6]. However, clinical utility of Ki-67 is limited by interobserver variability $[7,8]$, despite improvement by quality assurance $[9,10]$.

Since the advent of genomic signatures, efforts have been undertaken to integrate them into clinical routine for pN0-1 HR+ patients. Until 2015, most clinical evidence for genomic signatures derived from retrospective analyses of prospective trials conducted in the early-CT era [11-15] or used archived samples from untreated patients [16]. Considerable retrospective evidence exists for reproducible prognostic impact of Oncotype DX ${ }^{\circledR /}$ Recurrence Score ${ }^{\circledR}$ (RS), MammaPrint ${ }^{\circledR}$, EndoPredict ${ }^{\circledR}$, and Prosigna ${ }^{\circledR}$, but their value beyond centrally measured IHC markers or derived scores like IHC4 remains uncertain; $[4,5,17]$ the RS is the only test shown to predict CT benefit $[12,18]$.

While many national/international EBC guidelines incorporate genomic signatures [19], prospective trials exploring CT overtreatment/under-treatment are needed to assess benefits of augmenting conventional pathology with genomic signatures.

Recent prospective evidence has generally confirmed retrospective results: for MammaPrint ${ }^{\circledR}$, MINDACT [20]; for RS, the registry part of TAILORx (in N0 disease) [21]; and the WSG-PlanB three-year analysis in clinically highrisk EBC [22]. Nevertheless, the utility of genomic testing in high-risk patients and the optimal selection for these tests remain unclear.

PlanB is a prospective, randomised multicentre phase 3 $\mathrm{CT}$ trial in HER2-negative EBC. RS was prospectively assessed in HR+ patients; following an early amendment, $\mathrm{RS} \leq 11$ participants with $\leq 3$ involved lymph nodes (LN) could omit $\mathrm{CT} ; \mathrm{RS} \leq 11$ patients had excellent three-year survival [22]. The planned translational analyses included independent central pathology review of grade/IHC markers and their utilisation with RS for prognosis in nodal and KI-67 subgroups, based on the "five-year" (median 55-month) PlanB follow-up.

\section{Methods}

\section{Study participants}

The trial included female patients, $18-75$ years, with histologically confirmed, unilateral primary invasive BC, adequate surgical treatment (free margins, sentinel-node biopsy in node-negative, or axillary dissection in nodepositive patients), without evidence of metastasis. Key inclusion criteria: HER2-negativity; pT1-T4c; pN+ [or pN0 with a risk factor ( $\geq$ pT2, grade $2 / 3$, high uPA/PAI-1, $<35$ years, or HR-negative)]; ECOG performance status $<2$ or Karnofsky Index $\geq 80 \%$; signed informed consent; and (if $\geq 4$ positive LN, RS $>11$, or HR-negative) willingness to participate in the adjuvant CT PlanB trial.

\section{Study design}

WSG-PlanB was approved by German ethics boards and conducted in accordance with the Declaration of Helsinki. Clinicaltrials.gov identifier: NCT01049425.

PlanB (CONSORT diagram: Fig. 1) began in 2009 as a CT trial comparing anthracycline-containing (four cycles of epirubicin/cyclophosphamide followed by four cycles of 


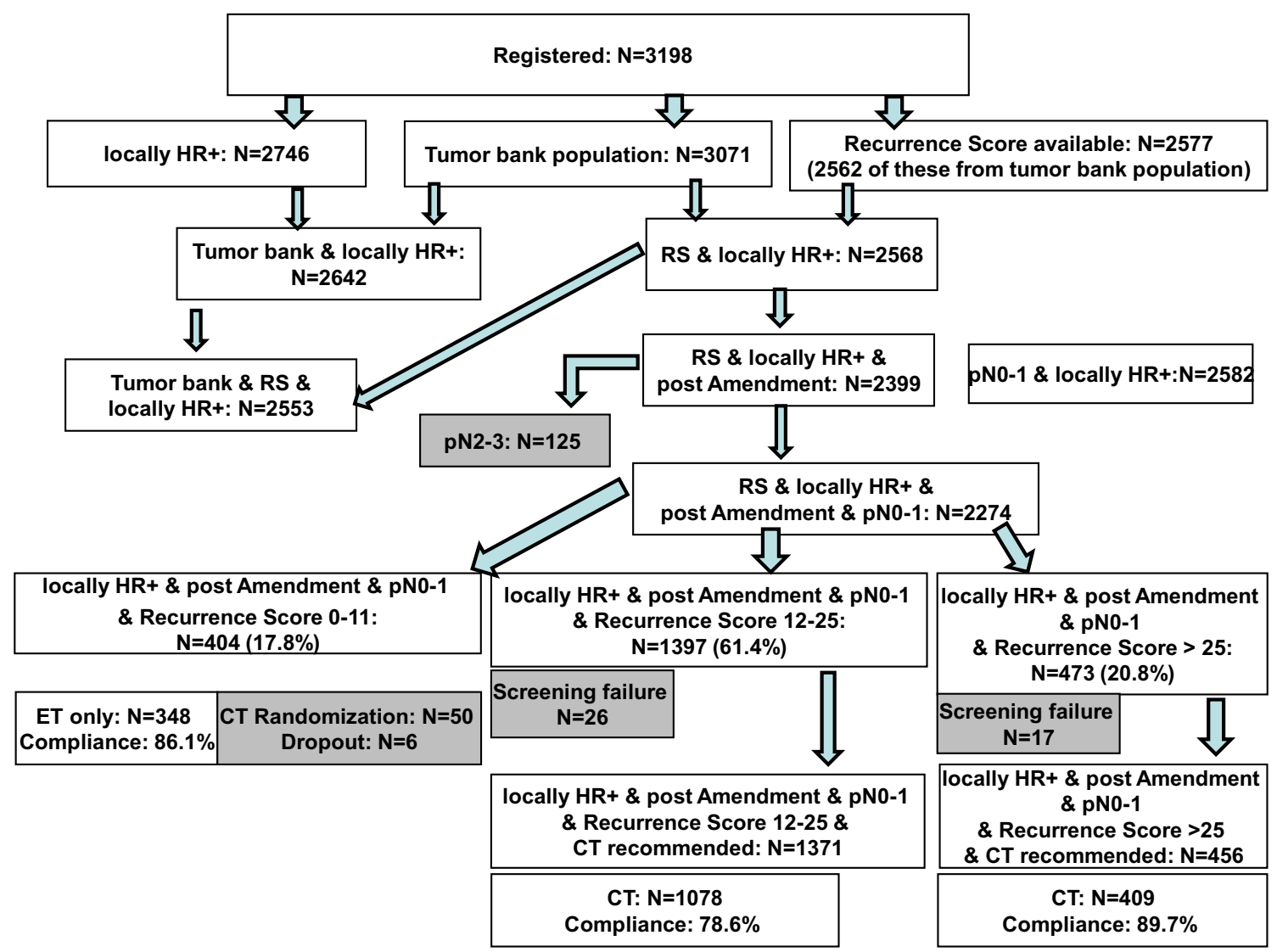

Fig. 1 PlanB CONSORT diagram. $C T$ chemotherapy, ET endocrine therapy, $H R$ hormone receptor, $R S$ recurrence score

docetaxel $\mathrm{q} 3 \mathrm{w}$ ) and anthracycline-free (six cycles of docetaxel/cyclophosphamide q3w) CT. After including 274 patients, the trial was amended (08/2009) to recommend endocrine therapy (ET) alone for $\mathrm{pN} 0 / \mathrm{pN} 1$, locally $\mathrm{HR}+$ patients with $\mathrm{RS} \leq 11$ (based on an initial RS validation study [11]).

Follow-up was performed at three-month intervals for the first three years and every six months thereafter. Data were obtained from electronic case record forms and verified by monitoring visits to the study sites.

RS was assessed on surgically removed primary tumour tissue at the central laboratory of Genomic Health Inc. (Redwood City, CA).

Slide review, IHC, and fluorescence in situ hybridisation were analysed in an independent central laboratory (Institute of Pathology, Hannover Medical School) [22]. Tumours were considered centrally ER+ (antibody SP-1) or PR+ (antibody PgR636, both Zytomed, Berlin, Germany) if immunostaining was present in $\geq 1 \%$ of tumour nuclei. Ki-67 was assessed centrally using rabbit monoclonal Ki-67 antibody 30-9 (Ventana Inc.Tucson, USA) on $\geq 100$ invasive tumour cells; the semi-quantitative procedure for Ki-67 produces values in 5\% increments. Hence, analysed semi-quantitative ranges Ki-67 $\leq 10 \%, \geq 40 \%$ correspond to quantitative $\mathrm{KI}-67 \leq 13.25 \%^{3}$, Ki$67>35 \%$ [23], respectively; analyses were also performed for semi-quantitative $\mathrm{Ki}-67$ ranges $<20 \%$ and $\geq 20 \%{ }^{6}$. IHC4 was computed as previously described [4, 17].

\section{Endpoints}

The endpoints included prospective evaluation of RS prognostic impact at follow-up target of five years: Clinical outcomes (disease-free survival [DFS], overall survival $[\mathrm{OS}])$ in $\mathrm{RS} \leq 11$ patients treated with ET alone, and prospective evaluation of the prognostic value of other parameters (Ki-67, IHC4 and histological grade [ElstonEllis] by local/central assessment). Study was performed according to the reporting recommendations for tumour marker prognostic studies (REMARK) guidelines [24].

\section{Statistical analysis}

For DFS analysis, an event was defined as any invasive cancer event or death (with/without recurrence). Estimates of five-year DFS or OS with approximate $95 \%$ confidence intervals [given in brackets] were obtained by the Kaplan- 
Meier method. Comparisons of DFS or OS among subgroups used pairwise log-rank tests (reported as significant for $p<0.05$ ).

Subgroup analyses were performed in $\mathrm{RS} \leq 11$, RS 12-25, RS $>25$, and in Ki-67 subgroups (see below). Univariate and multivariate (forward elimination) Cox proportional hazard models for DFS were estimated; RS, $\mathrm{Ki}-67$, ER, PR, and IHC4 were coded as continuous variables using fractional ranks. For a realistic measure of effect sizes, hazard ratios of fractionally ranked variables are reported for 75 th versus 25 th percentile. Factors with significant impact on DFS or OS are referred to as "prognostic". Nodal status was coded as pN1-3 vs nodenegative, $\mathrm{pN} 2-3$ versus $\mathrm{pN} 0-1$, and $\mathrm{pN} 3$ versus $\mathrm{pN} 0-2$; tumour stage was coded as pT2-4 versus pT1; local and central grades were coded as grade 3 versus grade $1-2$. Statistical analyses were performed using SPSS v.23 (IBM Corp., Armonk, NY).

\section{Role of the funding source}

The industry supporters in this trial had no role in study design, data collection, analysis/interpretation, writing, or decision to submit the manuscript. The authors (OG, UN, $\mathrm{NH}, \mathrm{RK}$ ) had full data access and hold final responsibility for manuscript submission.

\section{Results}

\section{Study participants}

From 4/2009 to 12/2011, 3198 patients were recruited from 93 centres; 2449 were randomised for CT. As previously reported [22], the central tumour bank population included 2642 locally HR + cases (97.4\% centrally confirmed). The analyses presented here focus on locally HR + patients (all $\mathrm{pN}$ ) unless otherwise stated. Their median age was 56 years; median tumour size was $19 \mathrm{~mm} ; 61.9 \%$ had central grade $2 ; 58.8 \%$ were $\mathrm{N} 0 ; 35.2 \%$ were $\mathrm{pN} 1 ; 6.0 \%$ were pN2-3; 2553 (96.6\%) had available RS: $17.4 \%$ $\mathrm{RS} \leq 11,58.4 \%$ RS 12-25, and 20.8\% RS > 25 (Table 1).

Within the 2274 locally HR+ pN0-1 post-amendment patients, 404 (17.8\%) had RS $\leq 11$; CT was omitted in 348 $(86.1 \%)$ of these patients: $238(68.4 \%) \mathrm{pNO}$ and 110 $(31.6 \%) \mathrm{pN} 1$.

435 tumours were HR-negative/HER2 - by central pathology (local HR-negative status centrally confirmed in 93.5\%).

Compliance with treatment recommendations within the trial was $95.2 \%$ for $\mathrm{pN} 0$ and $75.2 \%$ for $\mathrm{pN} 1$.

Median follow-up was 55 months (range 3-72 months).
Table 1 Patient characteristics in ER and/or PR positive population (by local assessment)

\begin{tabular}{|c|c|}
\hline Characteristic & $N=2642$ \\
\hline \multicolumn{2}{|l|}{ Age (years) } \\
\hline Median (range) & $56(25-77)$ \\
\hline \multicolumn{2}{|l|}{ Tumour size (mm) } \\
\hline Median (range) & $19(1.2-130)$. \\
\hline \multicolumn{2}{|l|}{ Nodal status [N (\%)] } \\
\hline pNO & $1554(58.8)$ \\
\hline $\mathrm{pN} 1$ & $930(35.2)$ \\
\hline $\mathrm{pN} 2$ & $122(4.6)$ \\
\hline $\mathrm{pN} 3$ & $36(1.4)$ \\
\hline \multicolumn{2}{|l|}{ Therapy $[\mathrm{N}(\%)]$} \\
\hline Endocrine & $348(13.0)$ \\
\hline Chemotherapy randomization & $1970(74.6)$ \\
\hline Out of study & $324(12.4)$ \\
\hline \multicolumn{2}{|l|}{$\mathrm{RS}$ result $[\mathrm{N}(\%)]$} \\
\hline$\leq 11$ & $459(17.4)$ \\
\hline $12-25$ & $1544(58.4)$ \\
\hline$>25$ & $550(20.8)$ \\
\hline Unknown & $89(3.4)$ \\
\hline \multicolumn{2}{|c|}{ Central hormone receptor status, $[\mathrm{N}(\%)]$} \\
\hline ER positive & $2118(89.7)$ \\
\hline PR positive & $1751(74.1)$ \\
\hline ER and/or PR positive & $2202(93.2)$ \\
\hline ER and PR negative & $57(2.4)$ \\
\hline Unknown & $160(6.8)$ \\
\hline \multicolumn{2}{|l|}{ Central grade $[\mathrm{N}(\%)]$} \\
\hline Grade 1 & $134(5.1)$ \\
\hline Grade 2 & $1636(61.9)$ \\
\hline Grade 3 & $825(31.2)$ \\
\hline Unknown & 47 (1.8) \\
\hline Median Ki-67 (\%) & 15 \\
\hline
\end{tabular}

$E R$ oestrogen receptor, $P R$ progesterone receptor, $R S$ recurrence score

\section{DFS in RS groups, impact of nodal status, and Ki-67 within these $\mathrm{RS}$ groups}

In locally $\mathrm{HR}+$ patients with follow-up (including all $\mathrm{pN})$, DFS was higher in RS $\leq 11$ and RS $12-25$ compared to RS $>25$ (both $p<0.001$ ); five-year DFS was 93.6\% [90.8-96.4\%] in low-RS (about three-fourths receiving no CT), $94.3 \%$ [92.8-95.8\%] in intermediate RS (all CT-treated), and 84.2\% [80.6-87.8\%] in high-RS patients (all CT-treated) (Fig. 2a). Five-year DFS in those RS $\leq 11$ patients treated with ET alone was $94.2 \%$ [91.2-97.3\%] and was similar in pNO $(\mathrm{n}=238)(94.2 \%$; [90.4-98.0\%]) and $\mathrm{pN} 1(\mathrm{n}=110)$ subgroups $(94.4 \%$; [89.5-99.3\%]). 

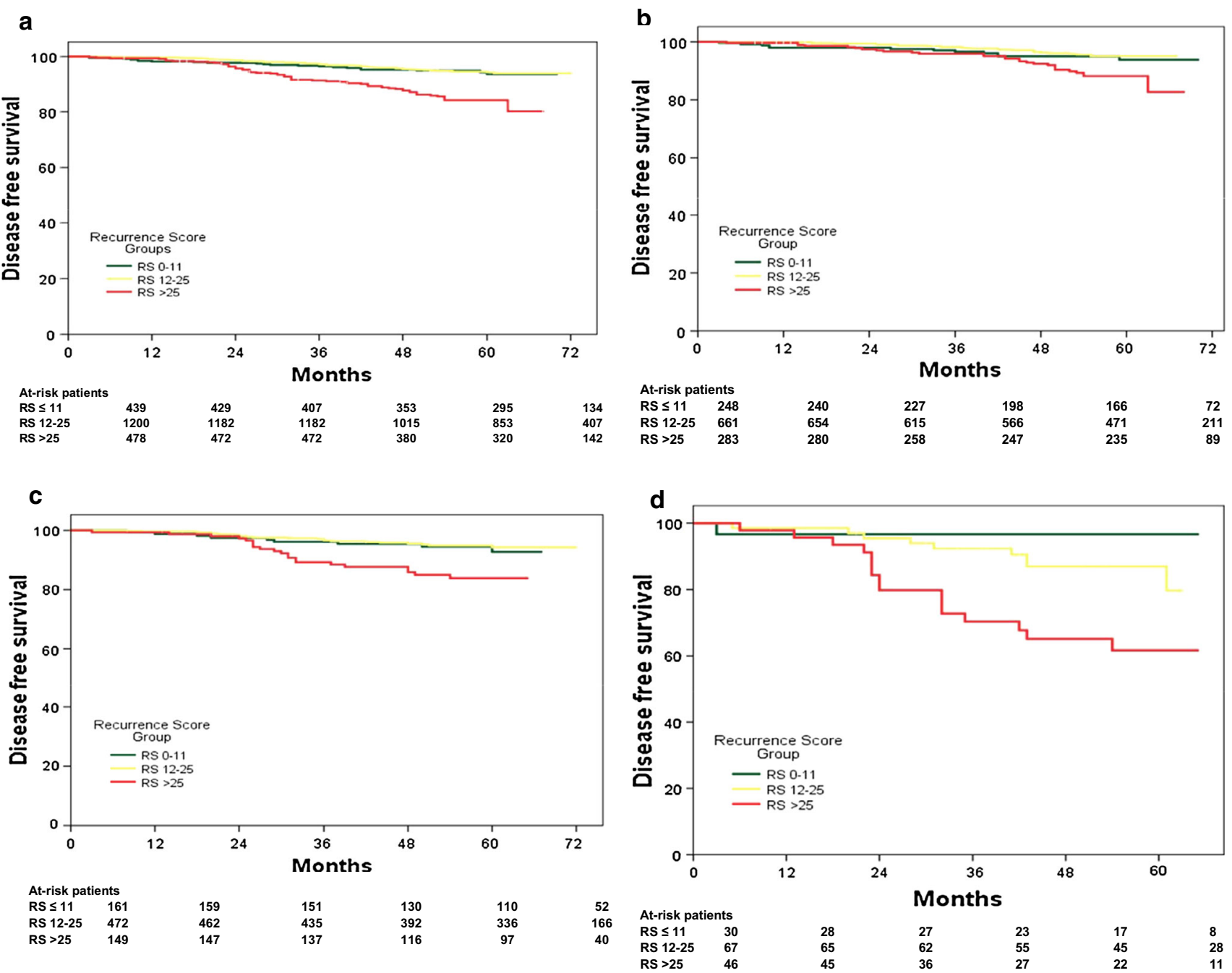

Fig. 2 DFS for patients with RS $\leq 11,12-25$, and $>25$ overall (a), node-negative patients (b), for patients with pN1 disease (c), and for patients with pN2-3 disease (d)

Higher DFS in $\mathrm{RS} \leq 11$ and $\mathrm{RS} 12-25$ compared to $\mathrm{RS} \geq 25$ patients held separately in N0, N1, and $\mathrm{N} 2+$ (Fig. 2b-d). In pN2-3 patients with $\mathrm{RS}>25$, fiveyear DFS was $61.7 \%$ [46.6-76.8\%].

Within RS subgroups, a significant impact of Ki-67 on DFS was seen only for RS $>25$. In terms of fractionally ranked $\mathrm{Ki}-67$, the hazard ratio ( 75 th to 25 th percentile) was 2.62 [1.39-4.91] ( $p=0.003)$, i.e. poorer DFS. The corresponding CI in low and intermediate RS were [0.39-3.01] and [0.87-2.82], respectively. (Similar results were seen for grouped $\mathrm{Ki}-67$ ).

\section{DFS in Ki-67 subgroups and impact of RS within these subgroups}

DFS was assessed (Appendix Fig. 5) in ("luminal") patients (all pN) with central HR+ and HER2-negative status and follow-up for the Ki-67 subgroups "low"
$(0-10 \%, \quad n=810), \quad$ "intermediate" $\quad(>10 \%, \quad<40 \%$, $n=988)$, and "high" ( $\geq 40 \%, n=74)$; and for comparison in triple-negative (TN) $(n=405)$ patients (central HR-negative and HER2-negative); CT was administered in $79.9 \%, 86.7 \%, 97.3 \%$, and $100 \%$, respectively. Five-year DFS rates were 94.7\% [92.9-96.6\%], 91.0\% [89.0-93.0\%], $73.4 \%$ [61.8-84.9\%], and 80.3\% [76.2\%-84.4\%], respectively $(p<0.003$ for "intermediate" versus "low" Ki-67, $p=0.5$ for "high" versus "TN", $p<0.001$ for the other four comparisons).

Figure 4 illustrates the impact of RS groups on DFS within the low-Ki-67 and intermediate Ki-67 subgroups defined above (there were only 62 patients with follow-up and measured RS in the entire high-Ki-67 subgroup, almost all with high RS, Table 2). Within the intermediate Ki-67 subgroup, RS $>25$ was associated with poorer DFS than either in RS $\leq 11$ or RS 12-25 (both $p<0.001$, log-rank); five-year DFS was $94.4 \% \quad$ [89.9-98.9\%], $93.8 \%$ 
Table 2 Joint distribution of recurrence score (RS) and semiquantitative $\mathrm{Ki}-67$ in the analysed population

\begin{tabular}{|c|c|c|c|c|c|c|c|c|c|}
\hline & \multicolumn{9}{|c|}{ (semi-quantitative) Ki-67 group } \\
\hline & $0-10 \%$ & $15 \%$ & $20 \%$ & $25 \%$ & $30 \%$ & $35 \%$ & $40 \%$ & $>40 \%$ & Total \\
\hline \multicolumn{10}{|l|}{$\mathrm{RS} \leq 11$} \\
\hline$N$ & 223 & 87 & 68 & 23 & 1 & 1 & 2 & 0 & 405 \\
\hline$\%$ of $\mathrm{Ki}-67$ group & $22.7 \%$ & $20.1 \%$ & $19.1 \%$ & $10.6 \%$ & $1.0 \%$ & $2.5 \%$ & $4.7 \%$ & $0.0 \%$ & $0.0 \%$ \\
\hline \multicolumn{10}{|l|}{ RS12-25 } \\
\hline$N$ & 680 & 283 & 219 & 108 & 42 & 16 & 5 & 2 & 1355 \\
\hline$\%$ of $\mathrm{Ki}-67$ group & $69.3 \%$ & $65.5 \%$ & $61.5 \%$ & $50.0 \%$ & $40.8 \%$ & $40.0 \%$ & $11.6 \%$ & $6.3 \%$ & $0.0 \%$ \\
\hline \multicolumn{10}{|l|}{$\mathrm{RS}>25$} \\
\hline$N$ & 78 & 62 & 69 & 85 & 60 & 23 & 36 & 30 & 443 \\
\hline$\%$ of $\mathrm{Ki}-67$ group & $8.0 \%$ & $14.4 \%$ & $19.4 \%$ & $39.4 \%$ & $58.3 \%$ & $57.5 \%$ & $83.7 \%$ & $93.8 \%$ & $0.0 \%$ \\
\hline \multicolumn{10}{|l|}{ Total } \\
\hline$N$ & 981 & 432 & 356 & 216 & 103 & 40 & 43 & 32 & 2203 \\
\hline$\%$ of RS group & $44.5 \%$ & $19.6 \%$ & $16.2 \%$ & $9.8 \%$ & $4.7 \%$ & $1.8 \%$ & $2.0 \%$ & $1.5 \%$ & $100.0 \%$ \\
\hline
\end{tabular}

[91.5-96.1\%], and 83.6\% [78.7-88.6\%] in these RS $\leq 11$, RS $12-25$, and RS $>25$ patients, respectively; the corresponding hazard ratios for RS $>25$ were 3.61 [1.61-8.13] versus $R S \leq 11$ and 2.82 [1.72-4.61] versus RS 12-25. Within the low-Ki-67 subgroup, an impact of RS was not seen, but only 33 events occurred in the whole low-Ki-67 subgroup (94.7\% five-year DFS, see above), and only $8.4 \%$ had high RS.

In pN0-1 patients, five-year DFS rates for Ki-67 low (0$10 \%)$, intermediate $(>10 \%,<40 \%)$, and high $(\geq 40 \%)$ were 95.0\% [93.1-96.8\%], 92.0\% [90.0-94.0\%], and 75.4\% [63.4-87.3\%], respectively. Within intermediate Ki-67 (but restricting to $\mathrm{pN} 0-1$ ), the relative impact of RS groups on DFS was as above: RS $>25$ was associated with poorer DFS than either RS $\leq 11$ or RS12-25 (both $p<0.001$, logrank). Five-year DFS was 94.5\% [89.8-99.3\%], 93.8\% [91.5-96.2\%], and $87.1 \%$ [82.3-91.9\%] in RS $\leq 11$, RS $12-25$, and RS $>25$ patients, respectively (pN0-1, intermediate Ki-67).

Separately for two subgroups defined by Ki-67 $\geq 20$ and Ki-67 $<20$ (St. Gallen-inspired cutoff), high-RS $(>25)$ patients had poorer DFS than low- or intermediate RS patients (all $\mathrm{pN}$ ): The hazard ratios for RS $>25$ versus RS 0-25 within Ki-67 $\geq 20 \%$ and Ki-67 $<20 \%$ subgroups were 2.69 [1.65-4.40] and 2.14 [1.07-4.26], respectively. Again, RS $\leq 11$ and RS12-25 subgroups had similar fiveyear DFS: 92.2 versus $92.3 \%$ for $\mathrm{Ki}-67 \geq 20 \%$ and 94.9 versus $95.1 \%$ for $\mathrm{Ki}-67<20 \%$, respectively.

\section{Univariate and multivariate analyses of DFS}

In univariate analyses of locally $\mathrm{HR}+$ patients with available RS (Table 2), nodal status (pN2-3 versus pN0-1, pN3 versus pN0-2), central and local grade 3 (vs. grade 1 or 2 ), tumour size $>2 \mathrm{~cm}$, as well as continuous, fractionally ranked RS, Ki-67, PR, and IHC, were all significant factors for DFS; higher levels of all these factors were unfavourable except for PR.

Table 3 also shows the results of a multivariate analysis including all the markers identified by univariate analysis (and fractionally ranked ER). Besides nodal status (pN2-3 vs. pN0-1, pN3 vs. pN0-2), grade 3 (independently by central and local assessment), tumour size $>20 \mathrm{~mm}$, and fractionally ranked $\mathrm{RS}$ - but not IHC4 or Ki-67-were independent factors for poorer DFS. The same results were true if analysis of the model was limited to chemotherapyonly-treated patients. When RS was excluded from the multivariate model, IHC4 or both $\mathrm{Ki}-67$ and PR became independent predictors for DFS. When local grade was excluded from the multivariate model, Ki-67 became independent prognostic factor for DFS.

\section{OS analysis by RS and nodal status}

Consistent with DFS, among all locally HR + patients with available RS, better OS was observed in $\mathrm{RS} \leq 11$ or RS12-25 patients than in RS $>25(p<0.001$ for both comparisons). Five-year OS (Fig. 3a) was $99.1 \%$ [98.5-100\%] in RS $\leq 11,97.2 \%$ [96.0-98.5\%] in RS 12-25, and $93.3 \%$ [90.8\%-95.8\%] in high-RS ( $>25)$ patients, despite only about one-fourth of these $\mathrm{RS} \leq 11$ patients receiving $\mathrm{CT}$, compared to all RS $>11$ patients; moreover, five-year OS in those $\mathrm{RS} \leq 11$ patients receiving ET alone was also $99.1 \%$. The differences correspond to quite substantial hazard ratios of 6.46 [2.27-18.42] for $\mathrm{RS}>25$ versus $\mathrm{RS} \leq 11$ and 3.26 [1.87-5.70] for RS $>25$ versus RS 12-25.

In node-negative patients, five-year OS was a remarkable $99.2 \%$ [98.0-100\%] in RS $\leq 11$ compared to $98.3 \%$ [97.0-99.5\%] in RS 12-25 and 96.7\% [94.4-99.0\%] in RS $>25$. OS in RS 12-25 was significantly higher than in 
Table 3 Univariate and multivariate analysis (DFS) for all locally HR + tumours with available RS

\begin{tabular}{|c|c|c|c|c|c|}
\hline Variable & Coding & Univariate HR (95\% CI) & $\mathrm{p}$ value & Multivariate HR $(95 \% \mathrm{CI})$ & $\mathrm{p}$ value \\
\hline RS & Fractionally ranked & $2.33(1.73-3.14)^{*}$ & $<0.001$ & $1.73(1.21-2.47)^{*}$ & 0.001 \\
\hline \multicolumn{6}{|l|}{ Nodal status } \\
\hline & $\mathrm{pN} 1-3$ vs pN0 & $1.55(1.11-2.15)$ & 0.009 & NS & \\
\hline & $\mathrm{pN} 2-3$ vs $\mathrm{pN} 0-1$ & $3.23(2.11-4.94)$ & $<0.001$ & $2.24(1.27-3.96)$ & 0.005 \\
\hline & $\mathrm{pN} 3$ vs $\mathrm{pN} 0-2$ & $6.35(3.34-12.07)$ & $<0.001$ & $2.88(1.27-6.52)$ & 0.011 \\
\hline Tumour stage & pT2-4 vs pT1 & $1.77(1.27-2.47)$ & 0.001 & $1.49(1.04-2.15)$ & 0.04 \\
\hline \multicolumn{6}{|l|}{ Grade } \\
\hline Local assessment & Grade $3 v s$ grade $1 / 2$ & $2.36(1.69-3.29)$ & $<0.001$ & $1.68(1.13-2.51)$ & 0.02 \\
\hline Central assessment & Grade $3 v s$ grade $1 / 2$ & $2.47(1.77-3.43)$ & $<0.001$ & $1.77(1.18-2.67)$ & 0.01 \\
\hline Ki-67 (\%), semi- quantitative & Fractionally ranked & $2.66(1.88-3.75)^{*}$ & $<0.001$ & NS & \\
\hline $\mathrm{ER}(\%)$ & Fractionally ranked & $0.75(0.53-1.05)^{*}$ & 0.10 & NS & \\
\hline PR $(\%)$ & Fractionally ranked & $0.53(0.39-0.72)^{*}$ & $<0.001$ & NS & \\
\hline IHC4 & Fractionally ranked & $2.04(1.47-2.83)^{*}$ & $<0.001$ & NS & \\
\hline
\end{tabular}

* 75th to 25 th percentile

$C I$ confidence interval, $E R$ oestrogen receptor, $H R$ hazard ratio, $N S$ nonsignificant, $P R$ progesterone receptor, $R S$ recurrence score Significant $p$ values are specified in bold

RS $>25$ patients within all nodal subgroups. OS in low-RS patients was also significantly higher than in high-RS patients within nodal subgroups 1-3 and 4-9 involved nodes (Fig. 3b-d).

\section{Discussion}

Our data provide the first prospective evidence in clinically high-risk EBC demonstrating strong impact of the RS on DFS and OS, not only in the collective as a whole, but also within key subgroups for clinical decision making. The independent impact of RS (as a continuous variable) on DFS was seen in a multivariate analysis including clinicopathological factors and IHC measurements. The observed survival impacts are particularly remarkable considering the PlanB trial design (CT omitted in a large fraction of $\mathrm{HR}+$, pN0-1 patients with $\mathrm{RS} \leq 11$ ); similarity of DFS in RS $\leq 11$ and RS12-25 subgroups might be attributable to mitigating effects of CT in all RS $>11$ (but only some RS $\leq 11$ ) patients.

Based on their excellent five-year DFS ( $>94 \%)$ and OS (>99\%), the omission of CT in 348 clinically high-risk (up to three involved $\mathrm{LN})$, genomically low-risk $(\mathrm{RS} \leq 11)$ patients seems justified. These favourable survival rates extend those of the explorative PlanB analysis after threeyear follow-up [22] and are consistent with the reported five-year invasive DFS of $93.8 \%$ and OS of $98 \%$ in the $\mathrm{RS}<11$ subgroup treated with ET alone from TAILORx (pN0 pT1-2 EBC) [21]. PlanB and TAILORx, the first prospective trials using RS for adjuvant decision making, also confirm previous retrospective data suggesting very low relapse rates in $\mathrm{RS}<18 \mathrm{pNO}-\mathrm{N} 1 \mathrm{EBC}$ patients without CT [11-13, 18].

MammaPrint $^{\circledR}$ is the only other genomic signature supported by a prospective trial (MINDACT) [20]. MINDACT met its primary objective, five-year distant DFS $>92 \%$ without adjuvant CT in patients with high clinical risk (AdjuvantOnline! 9.0) and low genomic risk, suggesting that $46 \%$ of the clinically high-risk population (including $46 \% \mathrm{pN} 1$ and/or $28.6 \%$ grade 3 tumours) may not require CT [20].

These prospective trials show that $\mathrm{CT}$ can be safely spared in a clinically meaningful fraction of HR +/HER2negative patients with $0-3$ affected $L N$ and low genomic risk. High tumour burden remained a strong unfavourable prognostic factor in PlanB; five-year DFS in $\mathrm{pN} 2+$ patients (a small group within PlanB) ranged from $100 \%$ (RS $\leq 11$ ) to $61 \%(\mathrm{RS}>25)$.

Our analyses add prospective evidence to the large body of consistent, yet retrospective/observational data for Oncotype DX including the SEER ( $>45,000$ patients) and Clalit registry $(n=2028)$ analyses. These studies demonstrated excellent five-year breast cancer-specific survival (BCSS) of $99-100 \%$ in RS $<18$ pN0 patients $(2-7 \%$ CT use) and $95-99 \%$ in RS $<18$ pN1 disease (7-41\% CT use, increasing from one to three positive LN) [25-27]. All studies observed poor outcome in RS $>25$ patients, indicating a need for further targeted therapies in this population.

PlanB is the first prospective study comparing the prognostic value of histological grade and IHC markers (ER, PR, Ki-67, and IHC4) determined by independent central pathology with that of a genomic signature in EBC. 

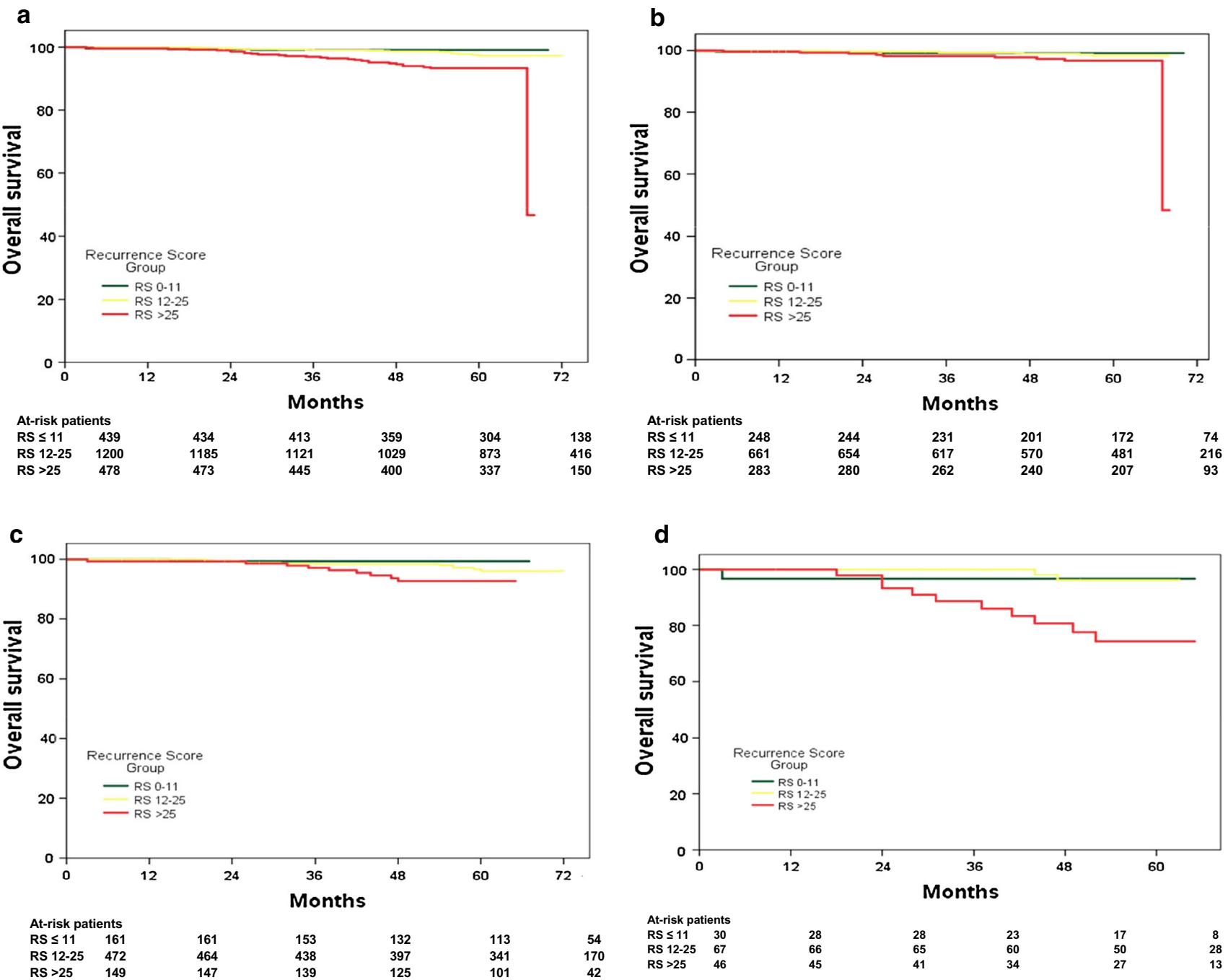

Fig. 3 OS for patients with RS $\leq 11,12-25$, and $>25$ overall (a), for node-negative patients (b), for patients with pN1 disease (c), and for patients with pN2-3 disease (d)

Our univariate/multivariate analyses confirm that these markers analysed by an experienced laboratory have prognostic value, if RS is excluded. However, RS eliminated all IHC markers (and IHC4) in multivariate analysis, consistent with most [4, 5], although not all [17] retrospective studies.

Consistent with Denkert et al. [23]., HR +/HER2-negative patients with $\mathrm{Ki}-67$ levels $\geq 40 \%$ had poor survival, similar to that of triple-negative patients. However, an unfavourable impact of higher Ki-67 on DFS was seen only in the RS $>25$ subgroup of locally HR+ patients, whereas no impact of Ki-67 was seen in corresponding RS $\leq 11$ and RS 12-25 subgroups.

Despite Ki-67 inter-laboratory/inter-observer variability [8], cutoff uncertainty (13.25 versus $20 \%)$ [3, 5, 28], and conflicting results regarding its predictive value concerning adjuvant CT benefit $[28,29]$, the St. Gallen Consensus currently includes Ki-67 for identifying luminal-A-like patients, who should not receive CT. Furthermore, several studies indicate that a substantial proportion of patients would be reclassified from luminal-A to luminal-B if genomic signatures were added to an IHC-based allocation [4, 30]. In PlanB, $10 \%$ of luminal-A-like tumours (i.e. Ki-67 $<20 \%$ ) had RS $>25$ [22], a high-risk group for whom CT is recommended.

CT indication based on IHC-defined luminal subtypes or grade is associated with substantial inter-observer variability, especially outside a central pathology setting [22]. It should thus be carefully re-evaluated given our prospective data demonstrating that the highly reproducible RS result outperforms IHC markers as a prognostic factor in EBC. However, the multivariate analysis suggests that genomic assays are best used in the context of established factors such as grade, nodal status, and tumour size. Ki-67, as determined by an experienced laboratory, seems to be useful for selecting patients for the more expensive genomic testing when financial resources are limited. That is because concordance between $\mathrm{RS}$ and $\mathrm{Ki}-67$ risk 
a

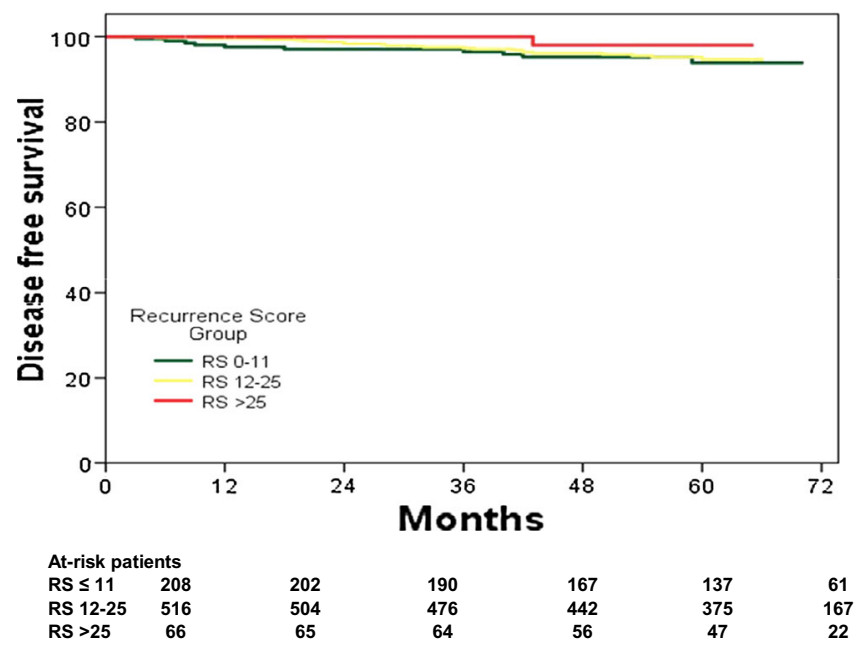

b

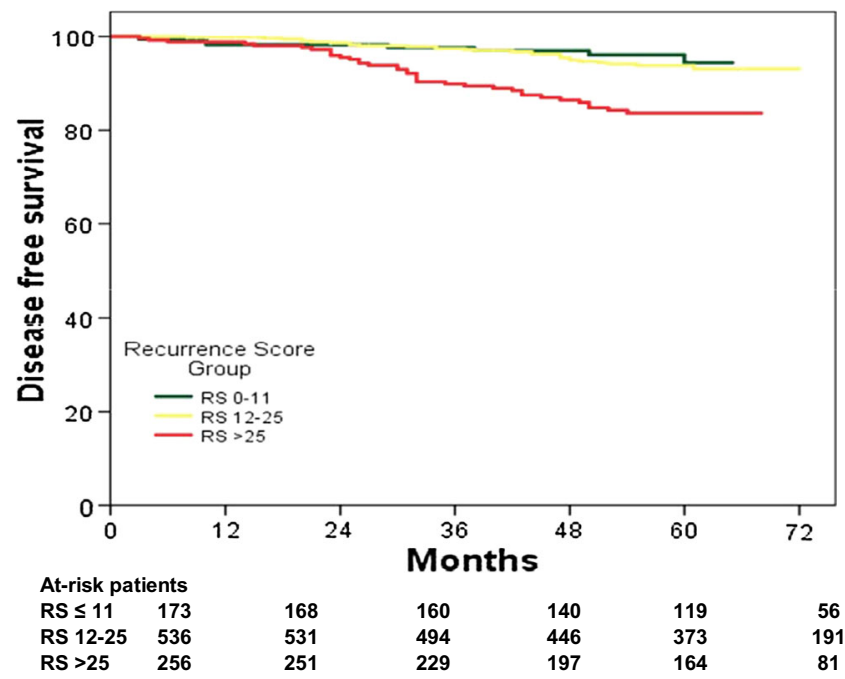

Fig. 4 DFS in HR+/Ki-67 0-10\% group (a) and in HR+/Ki-67 > 10\% and <40\% (b)

assessment is relatively high in the Ki-67 $\leq 10$ and $\geq 40 \%$ groups and the most prognostic value of RS was in the subgroup of intermediate Ki-67 ( $>10$ to $<40 \%)$. Hence, using genomic signatures may be particularly useful for intermediate/high-risk pN0-1 disease according to clinical and/or IHC markers. In clinically low-risk disease, using MammaPrint ${ }^{\circledR}$ is controversial due to the missing CT predictive effect within this group [20]. Using more than one signature per patient is currently not recommended.

Our results have some important limitations. First, this fiveyear follow-up, translational research analysis of the PlanB phase 3 trial is exploratory; the primary endpoint, comparing CT arms, will be reported subsequently. Second, so far, clinical consequences for $\mathrm{CT}$ omission can only be drawn for the relatively small group of $\mathrm{RS} \leq 11$, pN0-1 patients. Yet, approximately $60 \%$ of patients have RS $12-25$, where CT benefit is uncertain [31]. Two large prospective trials (TAILORx, RxPONDER) randomise patients to chemo-endocrine or ET alone within this RS range. The ongoing WSG-ADAPT trial uses dynamic proliferation response to preoperative ET as a selection tool for $\mathrm{CT}$ allocation in pN0-1 patients with intermediate RS (data availability: 2020).

In conclusion, the present findings regarding the PlanB five-year follow-up may be helpful in guiding/refining CT decisions in HR+/HER2-negative EBC, based on genomic signature and clinicopathological factors, particularly in pN0-1 patients otherwise considered as intermediate to high risk. The PlanB results support sparing adjuvant $\mathrm{CT}$ in pN0-1 patients with $\mathrm{RS} \leq 11$ (though possibly higher "clinical") risk. However, whereas five-year data seem sufficient for assessing early risk reduction mitigated by CT [1], longer follow-up is needed to explore questions such as the duration of adjuvant ET. The additional predictive impact of RS (or other genomic signatures) for late recurrence beyond that of clinicopathological factors is a complex and still controversial issue. Finally, additional targeted therapies (e.g. CDK $4 / 6$ inhibitors) need to be evaluated in pN0-1 luminal-B patients with high genomic risk who have significant residual risk despite adjuvant $\mathrm{CT}$.

Acknowledgements The study was supported by Genomic Health Inc, Sanofi Aventis, and Amgen. Medical editing support was provided by Avital Bareket-Samish, PhD, and funded by Genomic Health Inc. We thank all the study centres, patients, and pathologists for providing study materials. We also thank the teams of the WSG, Palleos, and central pathology lab at the MHH for their work.

Funding Genomic Health Inc, Sanofi Aventis, and Amgen.

\section{Compliance with ethical standards}

Conflict of interest HK received honoraria from Roche, Genomic Health, Novartis, and Astra-Zeneca. The West German Study group provided grant for central pathology work (to HK). RW received honoraria from Roche, Celgene, Novartis, Genomic Health, Amgen, MSD, Pfizer, and Pierre Fabre. NH received honoraria from Genomic Health, Nanostring and, Agendia. OG received honoraria from Genomic Health, Nanostring, and Roche. UN (as a representative of the WSG) received grants from Genomic Health, Sanofi Aventis, and Amgen for the conduct of the trial and received honoraria from Genomic Health, Agendia, Nanostring, Amgen, and Sanofi Aventis. $\mathrm{CL}$ and SK received honoraria from Genomic Health. All the other authors (TR, MJ, MC, MC) have declared that they have no conflict of interest. SS is an employee and a shareholder of Genomic Health (SS patent rights assigned to Genomic Health). CC is an employee of Genomic Health. All the other authors had nothing to disclose.

Open Access This article is distributed under the terms of the Creative Commons Attribution-NonCommercial 4.0 International License (http://creativecommons.org/licenses/by-nc/4.0/), which permits any noncommercial use, duplication, adaptation, distribution and reproduction in any medium or format, as long as you give appropriate credit to the original author(s) and the source, a link is provided to the Creative Commons license and any changes made are indicated. 


\section{Appendix}

See Fig. 5.

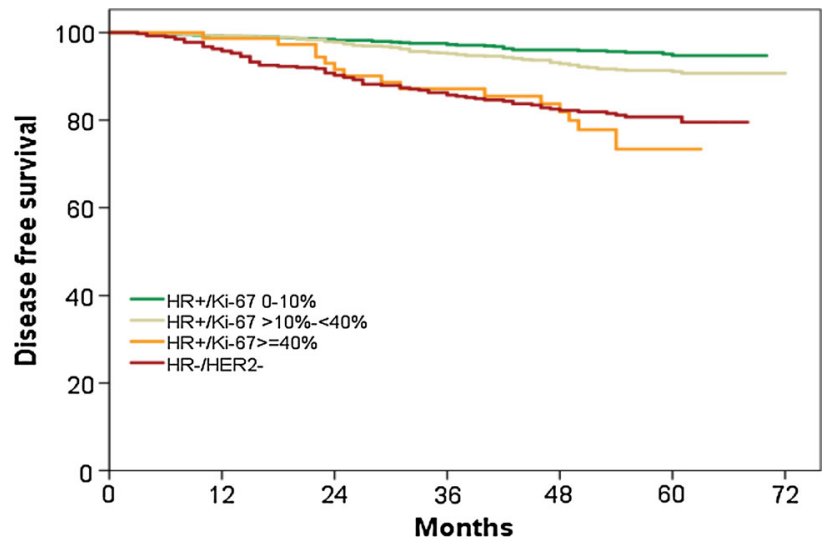

At risk patients

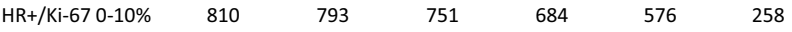

$\begin{array}{lllllll}\mathrm{HR}+/ \mathrm{Ki}-67>10-<40 \% & 988 & 974 & 908 & 805 & 675 & 343\end{array}$

$\begin{array}{lllllll}\mathrm{HR}+/ \mathrm{Ki}-67 \geq 40 \% & 74 & 72 & 65 & 53 & 45 & 17\end{array}$

$\begin{array}{lllllll}\text { HR-/HER2- } & 405 & 386 & 358 & 314 & 269 & 131\end{array}$

Fig. 5 DFS by central Ki-67 expression levels in centrally HR+ patients. DFS in the triple-negative (centrally ER/PR/HER2-negative) subgroup is included for comparison

\section{References}

1. Early Breast Cancer Trialists' Collaborative G (2005) Effects of chemotherapy and hormonal therapy for early breast cancer on recurrence and 15-year survival: an overview of the randomised trials. Lancet 365(9472):1687-1717. doi:10.1016/S01406736(05)66544-0

2. Perou CM, Sorlie T, Eisen MB, van de Rijn M, Jeffrey SS, Rees CA, Pollack JR, Ross DT, Johnsen H, Akslen LA, Fluge O, Pergamenschikov A, Williams C, Zhu SX, Lonning PE, Borresen-Dale AL, Brown PO, Botstein D (2000) Molecular portraits of human breast tumours. Nature 406(6797):747-752

3. Cheang MC, Chia SK, Voduc D, Gao D, Leung S, Snider J, Watson M, Davies S, Bernard PS, Parker JS, Perou CM, Ellis MJ, Nielsen TO (2009) Ki67 index, HER2 status, and prognosis of patients with luminal $B$ breast cancer. J Natl Cancer Inst 101(10):736-750. doi:10.1093/jnci/djp082

4. Prat A, Cheang MC, Martin M, Parker JS, Carrasco E, Caballero R, Tyldesley S, Gelmon K, Bernard PS, Nielsen TO, Perou CM (2013) Prognostic significance of progesterone receptor-positive tumor cells within immunohistochemically defined luminal A breast cancer. J Clin Oncol 31(2):203-209. doi:10.1200/JCO. 2012.43.4134

5. Gluz O, Liedtke C, Huober J, Peyro-Saint-Paul H, Kates RE, Kreipe HH, Hartmann A, Pelz E, Erber R, Mohrmann S, Mobus V, Augustin D, Hoffmann G, Thomssen C, Janicke F, Kiechle M, Wallwiener D, Kuhn W, Nitz U, Harbeck N, Investigators EC-D (2016) Comparison of prognostic and predictive impact of genomic or central grade and immunohistochemical subtypes or IHC4 in HR+/HER2- early breast cancer: WSG-AGO EC-Doc Trial. Ann Oncol 27(6):1035-1040. doi:10.1093/annonc/mdw070
6. Coates AS, Winer EP, Goldhirsch A, Gelber RD, Gnant M, Piccart-Gebhart M, Thurlimann B, Senn HJ, Panel M (2015) Tailoring therapies-improving the management of early breast cancer: St Gallen International Expert Consensus on the Primary Therapy of Early Breast Cancer 2015. Ann Oncol 26(8):1533-1546. doi:10.1093/annonc/mdv221

7. Varga Z, Diebold J, Dommann-Scherrer C, Frick H, Kaup D, Noske A, Obermann E, Ohlschlegel C, Padberg B, Rakozy C, Sancho Oliver S, Schobinger-Clement S, Schreiber-Facklam H, Singer G, Tapia C, Wagner U, Mastropasqua MG, Viale G, Lehr HA (2012) How reliable is Ki-67 immunohistochemistry in grade 2 breast carcinomas? A QA study of the Swiss Working Group of Breast- and Gynecopathologists. PloS one 7(5):e37379. doi:10. 1371/journal.pone.0037379

8. Dowsett M, Nielsen TO, A'Hern R, Bartlett J, Coombes RC, Cuzick J, Ellis M, Henry NL, Hugh JC, Lively T, McShane L, Paik S, Penault-Llorca F, Prudkin L, Regan M, Salter J, Sotiriou C, Smith IE, Viale G, Zujewski JA, Hayes DF, International Ki67 in Breast Cancer Working G (2011) Assessment of Ki67 in breast cancer: recommendations from the International Ki67 in Breast Cancer working group. J Natl Cancer Inst 103(22):1656-1664. doi:10.1093/jnci/djr393

9. Leung SCY, Nielsen TO, Zabaglo L, Arun I, Badve SS, Bane AL, Bartlett JMS et al (2016) Analytical validation of a standardized scoring protocol for Ki67: phase 3 of an international multicenter collaboration. NPJ Breast Cancer 2:16014

10. Polley MY, Leung SC, McShane LM, Gao D, Hugh JC, Mastropasqua MG, Viale G, Zabaglo LA, Penault-Llorca F, Bartlett JM, Gown AM, Symmans WF, Piper T, Mehl E, Enos RA, Hayes DF, Dowsett M, Nielsen TO, International Ki67 in Breast Cancer Working Group of the Breast International G, North American Breast Cancer G (2013) An international ki67 reproducibility study. J Natl Cancer Inst 105(24):1897-1906. doi:10.1093/jnci/ djt306

11. Paik S, Shak S, Tang G, Kim C, Baker J, Cronin M, Baehner FL, Walker MG, Watson D, Park T, Hiller W, Fisher ER, Wickerham DL, Bryant J, Wolmark N (2004) A multigene assay to predict recurrence of tamoxifen-treated, node-negative breast cancer. N Engl J Med 351(27):2817-2826

12. Paik S, Tang G, Shak S, Kim C, Baker J, Kim W, Cronin M, Baehner FL, Watson D, Bryant J, Costantino JP, Geyer CE Jr, Wickerham DL, Wolmark N (2006) Gene expression and benefit of chemotherapy in women with node-negative, estrogen receptor-positive breast cancer. J Clin Oncol 24(23):3726-3734. doi:10.1200/JCO.2005.04.7985

13. Dowsett M, Cuzick J, Wale C, Forbes J, Mallon EA, Salter J, Quinn E, Dunbier A, Baum M, Buzdar A, Howell A, Bugarini R, Baehner FL, Shak S (2010) Prediction of risk of distant recurrence using the 21-gene recurrence score in node-negative and node-positive postmenopausal patients with breast cancer treated with anastrozole or tamoxifen: a TransATAC study. J Clin Oncol 28(11):1829-1834. doi:10.1200/JCO.2009.24.4798

14. Gnant M, Filipits M, Greil R, Stoeger H, Rudas M, Bago-Horvath Z, Mlineritsch B, Kwasny W, Knauer M, Singer C, Jakesz R, Dubsky P, Fitzal F, Bartsch R, Steger G, Balic M, Ressler S, Cowens JW, Storhoff J, Ferree S, Schaper C, Liu S, Fesl C, Nielsen TO, Austrian B, Colorectal Cancer Study G (2014) Predicting distant recurrence in receptor-positive breast cancer patients with limited clinicopathological risk: using the PAM50 Risk of Recurrence score in 1478 postmenopausal patients of the ABCSG-8 trial treated with adjuvant endocrine therapy alone. Ann Oncol 25(2):339-345. doi:10.1093/annonc/mdt494

15. Filipits M, Rudas M, Jakesz R, Dubsky P, Fitzal F, Singer CF, Dietze O, Greil R, Jelen A, Sevelda P, Freibauer C, Muller V, Janicke F, Schmidt M, Kolbl H, Rody A, Kaufmann M, Schroth W, Brauch H, Schwab M, Fritz P, Weber KE, Feder IS, Hennig 
G, Kronenwett R, Gehrmann M, Gnant M, Investigators EP (2011) A new molecular predictor of distant recurrence in ERpositive, HER2-negative breast cancer adds independent information to conventional clinical risk factors. Clin Cancer Res 17(18):6012-6020. doi:10.1158/1078-0432.CCR-11-0926

16. van de Vijver MJ, He YD, van't Veer LJ, Dai H, Hart AA, Voskuil DW, Schreiber GJ, Peterse JL, Roberts C, Marton MJ, Parrish M, Atsma D, Witteveen A, Glas A, Delahaye L, van der Velde T, Bartelink H, Rodenhuis S, Rutgers ET, Friend SH, Bernards R (2002) A gene-expression signature as a predictor of survival in breast cancer. N Engl J Med 347(25):1999-2009

17. Cuzick J, Dowsett M, Pineda S, Wale C, Salter J, Quinn E, Zabaglo L, Mallon E, Green AR, Ellis IO, Howell A, Buzdar AU, Forbes JF (2011) Prognostic value of a combined estrogen receptor, progesterone receptor, Ki-67, and human epidermal growth factor receptor 2 immunohistochemical score and comparison with the Genomic Health recurrence score in early breast cancer. J Clin Oncol 29(32):4273-4278. doi:10.1200/JCO.2010. 31.2835

18. Albain KS, Barlow WE, Shak S, Hortobagyi GN, Livingston RB, Yeh IT, Ravdin P, Bugarini R, Baehner FL, Davidson NE, Sledge GW, Winer EP, Hudis C, Ingle JN, Perez EA, Pritchard KI, Shepherd L, Gralow JR, Yoshizawa C, Allred DC, Osborne CK, Hayes DF (2010) Prognostic and predictive value of the 21-gene recurrence score assay in postmenopausal women with nodepositive, oestrogen-receptor-positive breast cancer on chemotherapy: a retrospective analysis of a randomised trial. Lancet Oncol 11(1):55-65. doi:10.1016/S1470-2045(09)70314-6

19. Markopoulos C, van de Velde C, Zarca D, Ozmen V, Masetti R (2016) Clinical evidence supporting genomic tests in early breast cancer: Do all genomic tests provide the same information? Eur $\mathbf{J}$ Surg Oncol. doi:10.1016/j.ejso.2016.08.012

20. Cardoso F, van't Veer LJ, Bogaerts J, Slaets L, Viale G, Delaloge S, Pierga JY, Brain E, Causeret S, DeLorenzi M, Glas AM, Golfinopoulos V, Goulioti T, Knox S, Matos E, Meulemans B, Neijenhuis PA, Nitz U, Passalacqua R, Ravdin P, Rubio IT, Saghatchian M, Smilde TJ, Sotiriou C, Stork L, Straehle C, Thomas G, Thompson AM, van der Hoeven JM, Vuylsteke P, Bernards R, Tryfonidis K, Rutgers E, Piccart M, Investigators M (2016) 70-Gene Signature as an Aid to Treatment Decisions in Early-Stage Breast Cancer. N Engl J Med 375(8):717-729. doi:10.1056/NEJMoa1602253

21. Sparano JA, Gray RJ, Makower DF, Pritchard KI, Albain KS, Hayes DF, Geyer CE Jr, Dees EC, Perez EA, Olson JA Jr, Zujewski J, Lively T, Badve SS, Saphner TJ, Wagner LI, Whelan TJ, Ellis MJ, Paik S, Wood WC, Ravdin P, Keane MM, Gomez Moreno HL, Reddy PS, Goggins TF, Mayer IA, Brufsky AM, Toppmeyer DL, Kaklamani VG, Atkins JN, Berenberg JL, Sledge GW (2015) Prospective Validation of a 21-Gene Expression Assay in Breast Cancer. N Engl J Med 373(21):2005-2014. doi:10.1056/NEJMoa1510764

22. Gluz O, Nitz UA, Christgen M, Kates RE, Shak S, Clemens M, Kraemer S, Aktas B, Kuemmel S, Reimer T, Kusche M, Heyl V, Lorenz-Salehi F, Just M, Hofmann D, Degenhardt T, Liedtke C, Svedman C, Wuerstlein R, Kreipe HH, Harbeck N (2016) West German Study Group phase III planB Trial: first prospective outcome data for the 21-gene recurrence score assay and concordance of prognostic markers by central and local pathology assessment. J Clin Oncol. doi:10.1200/JCO.2015.63.5383

23. Denkert C, Loibl S, Muller BM, Eidtmann H, Schmitt WD, Eiermann W, Gerber B, Tesch H, Hilfrich J, Huober J, Fehm T,
Barinoff J, Jackisch C, Prinzler J, Rudiger T, Erbstosser E, Blohmer JU, Budczies J, Mehta KM, von Minckwitz G (2013) Ki67 levels as predictive and prognostic parameters in pretherapeutic breast cancer core biopsies: a translational investigation in the neoadjuvant GeparTrio trial. Ann Oncol 24(11):2786-2793. doi:10.1093/annonc/mdt350

24. McShane LM, Altman DG, Sauerbrei W, Taube SE, Gion M, Clark GM, for the Statistics Subcommittee of the NCIEWGoCD (2005) Reporting recommendations for tumor marker prognostic studies (REMARK). J Natl Cancer Inst 97(16):1180-1184. doi:10.1093/jnci/dji237

25. Petkov V, Miller DP, Howlader N (2016) Breast-cancer-specific mortality in patients treated based on the 21-gene assay: a SEER population-based study. NPJ Breast Cancer 2:16017

26. Stemmer SM, Steiner M, Rizel S, Soussan-Gutman L, Geffen DB, Nisenbaum B, Ben-Baruch N, Isaacs K, Fried G, Rosengarten O, Uziely B, Svedman C, Rothney M, Klang S, Ryvo L, Kaufman B, Evron E, Zidan J, Shak S, N. L (2015) Real-life analysis evaluating $1594 \mathrm{~N} 0 / \mathrm{Nmic}$ breast cancer patients for whom treatment decisions incorporated the 21-gene recurrence score result: 5-year KM estimate for breast cancer specific survival with recurrence score results $\leq 30$ is $>98 \%$. Paper presented at the San Antonio Breast Cancer Symposium (SABCS), San Antonio, TX, Dec 8-12, 2015

27. Roberts MC, Miller DP, Shak S, Petkov VI (2017) Breast cancerspecific survival in patients with lymph node-positive hormone receptor-positive invasive breast cancer and Oncotype DX Recurrence Score results in the SEER database. Breast Cancer Res Treat. doi:10.1007/s10549-017-4162-3

28. Nielsen TO, Jensen MB, Burugu S, Gao D, Tykjaer Jorgensen CL, Balslev E, Ejlertsen B (2016) High risk premenopausal Luminal A breast cancer patients derive no benefit from adjuvant cyclophosphamide-based chemotherapy: results from the DBCG77B clinical trial. Clin Cancer Res. doi:10.1158/10780432.CCR-16-1278

29. Viale G, Regan MM, Mastropasqua MG, Maffini F, Maiorano E, Colleoni M, Price KN, Golouh R, Perin T, Brown RW, Kovacs A, Pillay K, Ohlschlegel C, Gusterson BA, Castiglione-Gertsch M, Gelber RD, Goldhirsch A, Coates AS, International Breast Cancer Study G (2008) Predictive value of tumor Ki-67 expression in two randomized trials of adjuvant chemoendocrine therapy for node-negative breast cancer. J Natl Cancer Inst 100(3):207-212. doi:10.1093/jnci/djm289

30. Wuerstlein R, Sotlar K, Gluz O, Otremba B, von Schumann R, Witzel I, Schindlbeck C, Janni W, Schem C, Bauerfeind I, Hasmueller S, Tesch H, Paulenz A, Ghali N, Orujov E, Kates RE, Cowens W, Hornberger J, Pelz E, Harbeck N (2016) The West German Study Group Breast Cancer Intrinsic Subtype study: a prospective multicenter decision impact study utilizing the Prosigna assay for adjuvant treatment decision-making in estrogenreceptor-positive, HER2-negative early-stage breast cancer. Current medical research and opinion. doi:10.1185/03007995. 2016.1166102

31. Penault-Llorca FM, Filleron T, Asselain B, Baehner FL, Fumoleau P, Lacroix-Triki M, Butler SM, Jamshidian F, Cherbavaz DB, Shak S, Roca L, Sagan C, Lemonnier J, Martin A-L, Roche HR (2014) Prediction of recurrence with the Oncotype DX recurrence score in node-positive, HR-positive, breast cancer patients treated with adjuvant chemotherapy: results from PACS01 trial. J Clin Oncol 32:11052 